\title{
PROBLEMS OF NEGLECTED PLACES UNDER BRIDGES: A CASE STUDY OF YEREVAN BRIDGE, BEIRUT, LEBANON
}

\author{
MAGED YOUSSEF \\ Faculty of Architecture - Design \& Built Environment, Beirut Arab University, Lebanon
}

\begin{abstract}
The bridge is the symbol of the obstacle that has been crossed, and the ability of man to overcome blockages of nature via technological development, which makes it a remarkable architectural element. Its urban features are multiple providing an outstanding potential for cities. Despite the importance of the bridge as infrastructure, unfortunately in some cities in developing countries, its problem is the impact on the urban environment that causes poor conditions to the spaces underneath by blocking light and air, brings blight to the surrounding areas, and creates undefined, unclear, fuzzy spaces that often are misused. These spaces become negative, undesirable, and unwanted by communities. The inhabited bridge or "überbautenbrücken", known as a hybrid structure - due to the fact that it bears many functions in addition to the mere crossing - has added to its multiple values the concept of inhabitation, and has revealed a new potential by bringing it closer to mankind: a certain "humanization". This paper, therefore, aims to produce solutions to develop the neglected places under bridges by turning them into potential urban spots. Subsequently, it works on drawing out the various urban qualities of bridges. As a case stud y the paper analyzes and surveys Yerevan Bridge in the Bourj Hammoud Area, Beirut, Lebanon, trying to produce solutions for the neglected areas beneath it through the transformation to an inhabited bridge. Through these solutions, the paper envisages innovative ideas susceptible to enlightening the path, or even participating to the rebirth of the concept of an inhabited bridge.

Keywords: architecture, bridge, neglected places, infrastructure, superstructure, habitation.
\end{abstract}

\section{INTRODUCTION}

'Ponte Vecchio', the Italian bridge, and 'Überbautenbrücken', the German term are the first images that pop up to one's mind when tackling the topic of inhabited bridges. The first one refers to the old bridge in Florence, while the second means constructing bridges (a German word designating the bridges on which constructions are erected.) Before appearing in the middle ages, bridges were mere crossing elements, subjects of fascination, or even symbol of technological progress and openness to the world. With the advent of inhabited bridges, the bridge was allocated with new commercial, cultural, and residential functions and became a multifunctional and versatile location. Such synergy between engineering and architecture embodied by inhabited bridges added a sense of real "magic" to the newly formed spaces. The inhabited bridge is an outstanding architectural type, very special and hybrid; whereas it became, with a simple crossing infrastructure, a real urban event, creating an artificial terrain and offering a new way of living. With the expansion of cities, the concept of separating functions leads to the quasiextinction of the inhabited bridge model. Dreams of living above a barrier attract the attention of designers. It was envisioned through the utopian urban proposals of the $19^{\text {th }}$ and $20^{\text {th }}$ centuries. Analysis of cities shows that bridges form a negative aspect of infrastructure regarding discontinuity created within the urban fabric and the consequent social and cultural discontinuity. The problem this research sheds the light on is the places located under bridges. Unfortunately, in developing countries, these places are mostly dark, unhealthy, dust-collectors, and occupied by street vendors, 
beggars, and homeless people, as shown in Fig. 1. This paper, therefore, aims to investigate a strategy to turn these neglected places under bridges from negative spots into advantageous potentials for a high-density zone. This strategy may restore the relationship between cities through designing inhabited bridges. Thus, this research hypothesizes that turning a bridge to an inhabited hub gathering commercial, residential, and cultural activities can overcome disadvantages of places located underneath and may improve quality of life within the surrounding built environment. As a detailed case study, the paper will analyze the situation of one of the bridges in Beirut, Lebanon, surveying its architectural and social status quo, recognizing its users, in order to deduct an effective strategy that can be applied on similar conditions.

\section{LITERATURE VIEW}

It is necessary to develop the notion of inhabited bridges as a literature review to recognize the previous ideas that can be useful to be re-used now. According to Cambridge Dictionary, a bridge' is a structure that is built over a river, road, or railway to allow people and vehicles to cross from one side to another. It is something that makes it easier to make a change from one situation to another. Architects and planners define it as "a construction, a work linking two points which are separated by a depression or an obstacle", and 'inhabited' is derived from the verb inhabit, means live, occupy, or dwell [1]. Hence, an inhabited bridge is a construction linking two separate points or may occupy a certain space or remain therein. The Belgium architect, Jean Dethier, explains that:

Inhabited bridges of yesterday and today; there is no precise designation for labeling such bridges, whether in English, French or Italian. In these three languages, for lack of anything better, the terms "inhabited bridges", "Ponts habités", and "Ponti Abitati" are used. Only the German language uses an appropriate word, which comprises, in principle, all the typological variations of the bridges in which we are interested in the present context; überbautenbrücken; whereas it designates indeed the set of bridges on which buildings are erected. Each inhabited bridge has a twofold component and comprises an infrastructure (the platform which strides over the obstacle) and an architectural superstructure. As such, the latter vests upon the whole-package a functional, economic and social "surplus", as well as a cultural, symbolic and affective surplus [2].

Within such a German word, 'überbautenbrücken', the inhabited bridge comprises the work of two built elements: the bridge and the construction. Coexistence of both architectural elements gives birth to a new architectural element: the inhabited bridge.

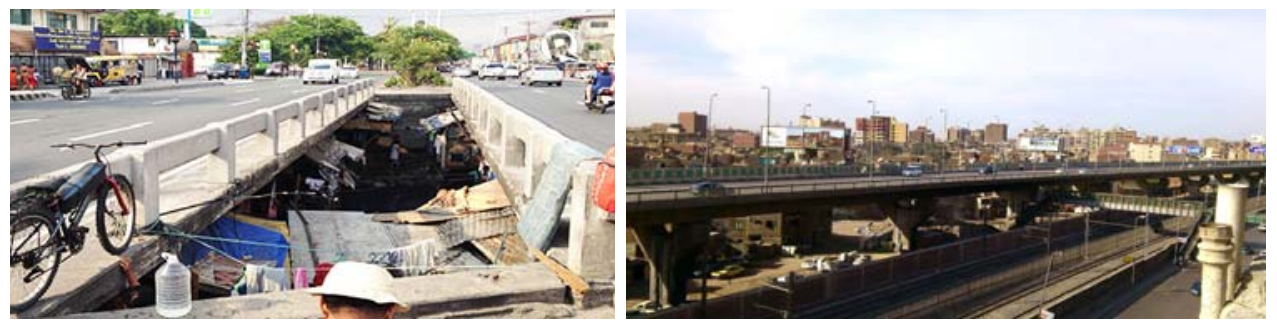

Figure 1: (a) On the left - Quirino Bridge is a home to more than 100 families living underneath, Manila, Philippines. (Photographed by Jodesz Gavilan and Rappler.) (b) On the right - Empty and underused spaces under $6^{\text {th }}$ of October Bridge, Cairo, Egypt. (Photographed by Marwan Abd-Elrahman.) 


\subsection{Historical context of the 'Inhabited Bridges'}

The first inhabited bridges appeared in the Middle Ages, especially in Europe at the $9^{\text {th }}$ century and remained until $17^{\text {th }}$ century. The $18^{\text {th }}$ century witnessed building of the last living bridge, designed by Robert Adam in Bath, England. In Paris 1141, the king ordered currency exchangers to establish their offices on the Great Bridge. All types of buildings were built back then: dwellings, trades and even cult places. Urban inhabited bridges become economic and commercial centers, though dwellings were also often erected on the bridge due to the fact that the merchants who developed their activities also built their dwellings above their workplaces". Beside the defensive function of some bridges, different functions were added up on the roadways of Middle Age bridges; hence the concept of chapel-bridge was born. Moreover, fortified bridges are inhabited bridges, such as Tower Bridge in London. Fortified bridges played an essential role in the defensive strategy of the city which blocked the enemy. There are also the rural inhabited bridges or the fancy bridges that were built on private lands and served as castles or gardens. Historically, the inhabited bridge is a specific typology of bridges of West Europe. The most relevant countries are France, England and Italy. In the USA, a hub of mega structures, such model of bridges was not discovered before the $20^{\text {th }}$ century, though for quite different reasons [3].

\subsection{An example of the 'Inhabited Bridges'}

As shown in Fig. 2, one of the well-known inhabited bridges is 'Ponte Vecchio Bridge' in Florence, Italy. It crosses Arno River. According to Giorgio Vasari, Taddeo Gaddi was the architect of this bridge. After the erection of city walls in 1177, the bridge accommodated a chapel, dwellings and 43 shops. In 1593, Duke Ferdinand suggested to let these shops offer luxurious products like jewelry. A new corridor was established in 1565 (a kind of covered gallery) passing through the upper floor and serving as the prince's private passage between the castle and the offices. In 1850, a suggestion was posed to restore Ponte Vecchio through a metal and glass structure according to a development plan of Florence. This plan was not executed in order to preserve symbolism of the bridge and identity of the city. Ponte Vecchio Bridge still preserves its initial form and function, and remains a living witness of the important medieval inhabited bridges [4].

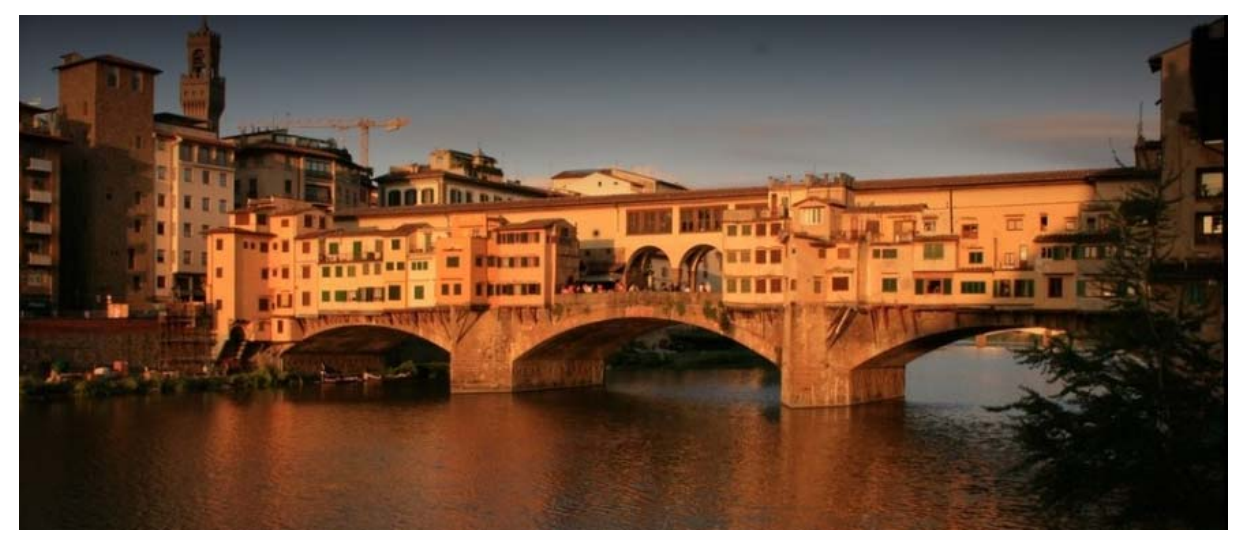

Figure 2: Ponte Vecchio Bridge' in Florence is an example of the inhabited bridges. (Photo credit to Lourdes Flores - uploaded on the website: www.visitflorence.com.) 


\subsection{Typological criteria of inhabited bridges projects}

Inhabited bridges are diverse; therefore, it is practically difficult to suggest a general typology. Each inhabited bridge may be classified back to its affiliation, which grants its "genetic code". Typological analysis to transform a bridge to an inhabited one can be based on certain criteria: physical dimensions, nature of the overcome obstacle, link between bridge and ground, flow, infrastructure, influence of infrastructure on the superstructure, the program and the urban role. This research focuses only on three of them as follows:

\subsubsection{Nature of the overcome obstacle}

Bridges are overcoming four categories of obstacles such as; water streams, depressions, infrastructures and urban tissues. The first two are natural disconnections which represent part of the ground, difficult for the urban condition, leading to usage of infrastructure for any access to the superstructure. The third is linked to the urban road network, while the fourth requires integration of any superstructure within its context.

\subsubsection{Bridge and ground}

A simple bridge, as a road infrastructure, is linked to the ground through its connection to the roadway network. Links to the ground differ according to the inhabited bridge. Hence, the relation between infrastructure and the bridge as a superstructure can be integrated more through the link with the context, such as Galata Bridge in Istanbul, Turkey, shown Fig. 3. This bridge gathers two functions; the first as a roadway on the upper level, and the second as a restuarants-boulivard on the lower level connecting between the two levels with vertical ciruculation elements.

\subsubsection{Urban role}

Inhabited bridge may be defined as a system of different elements: infrastructure, stream, and superstructure. It may be identified as 'an urban element, a fragment of a city'. Inhabited bridges are grouped according to their urban role, whereas each of them may play various roles at the same time [5].

After presenting a literature review on inhabited bridges that emerged without any noticeable problems of places underneath, the paper analyzes a case study following a scientific methodology as follows.

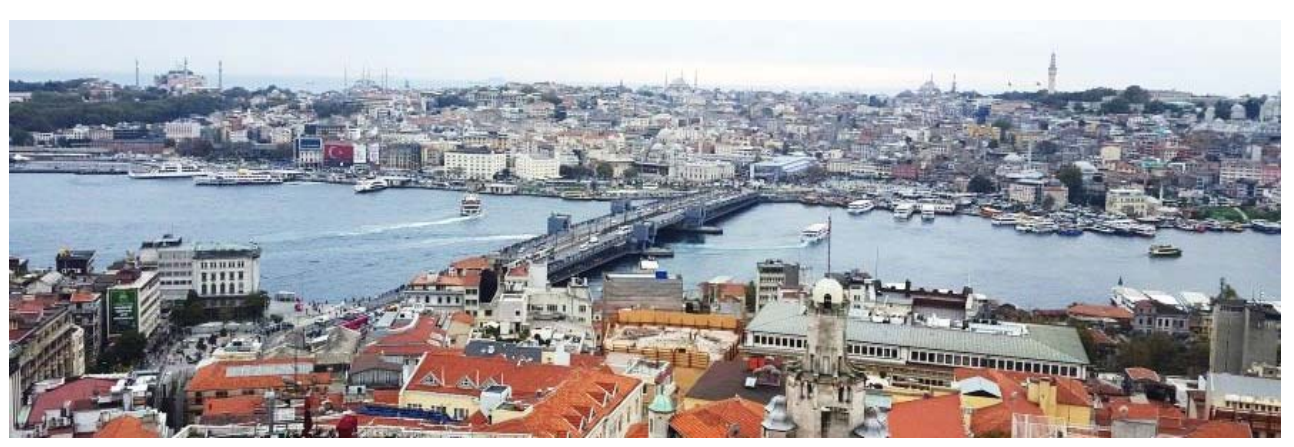

Figure 3: Galata bridge in Istanbul, Turkey - A link between two levels. (Photographed by the author, November 2015 - The photo was taken from Galata Tower). 


\section{METHODOLOGY}

This paper follows three scientific research methods; first: the field method concentrating on a case study, surveying its site, taking photographs, and making faceto-face interviews. Second: the analytical methodology depends on analyzing the information that had been collected from the field survey. Third: the deductive methodology trying to deduct a strategy that may overcome problems of the neglected places under bridges through transforming bridges to be inhabited and full of different activities. The case study is Yerevan Bridge in Bourj Hammoud area, Beirut, Lebanon.

\subsection{Introducing the case study of 'Yerevan Bridge', Bourj Hammoud Area, Beirut}

After 16 years of Lebanon Civil War, Beirut went through an extensive reconstruction phase. Projects focused on reviving the city and improving its urban condition. Infrastructure projects took part in the reconstruction phase aiming to serve the city center. These projects were carried out without any concern to their impact on the urban environments of other areas in the city. In contrast to the fast development of the city center, most of the peripheral areas, shown in Fig. 4 - misery belt - of Beirut that present a patchwork of confessional, social, and economical fragments, became marginalized. 'Bourj Hammoud Area' belongs to the misery belt [6].

This area is a suburb in Beirut, located between large national lines and Beirut River. It is located on the Mediterranean coast, $2 \mathrm{~km}$ to the east of Beirut Central District. This town covers $2 \mathrm{~km}^{2}$ with a population of 150,000 inhabitants. This route aims at connecting the Central District of the capital to the region of Metn [6]. Heavy traffic due to the national roads crossing the city, active trade and misused shorelines are mere examples of elements which impose substantial problems to this residential area. Interest is focused on those caused by the passage of the access road PN1 known as 'Yerevan Bridge'. It goes through the heart of the neighborhood, cutting out a previously homogeneous urban fabric, while creating on the ground a long "dead" strip of empty space, under the bridge, and representing a source of pollution for countless neighboring residential buildings. It disrupts life of the community and specifically the neighboring districts of the bridge, given the fact

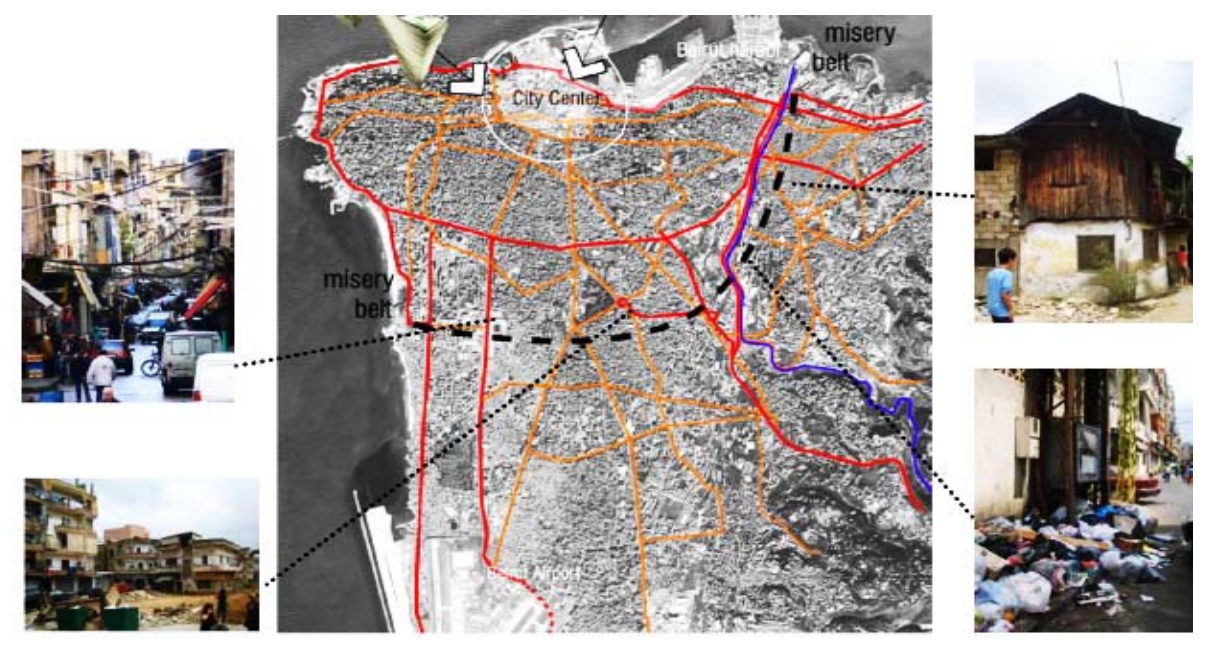

Figure 4: All investments were focused on the city, leaving the less for truncate areas along the 'misery belt' with low living conditions. 
that it skims the balconies of apartments. It represents a real barrier, creating fictitious edges to the city. However, the bridge area seems like a question mark for many people: starting with the city municipality, residents of the area, users of the space, and even urban professionals who condemn places under the bridge as dead zones. Yerevan Bridge remains an important connector between two vivid districts and penetrates a massive crowd area.

As shown in Fig. 5, the Bourj Hammoud Area was started by settlements of Armenian refugees from 1924. In 1975, the train services stopped in it. Lately, in 2008, with the end of the Civil War, new reconstruction projects had been initiated.

\subsection{Features of 'Yerevan Bridge'}

Yerevan Bridge links between two districts; Achrafieh and Dekwaneh. It passes through the residential area of Bourj Hammoud and neighboring buildings alongside it. With 18 meters in width, more than 2 kilometers long, this route cuts its path through the heart of urban entity within this space. As shown in Fig. 6, the bridge was built by mushroom columns sliding by the buildings [7].

By analyzing the physical presentation of the bridge, the main material of construction is reinforced concrete. Distance between supports is approximately 25 meters which prevent light. Headroom, the distance between the lower part of the structure and the ground, is unused height; approximately 7.5 meters. Dar El Handasah was the architect, and Mr.
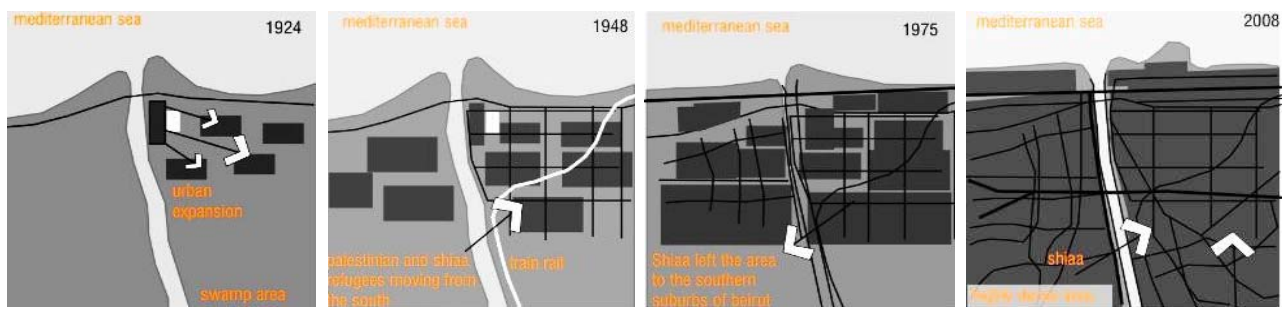

Figure 5: From left to right - The chronological phases of 'Bourj Hammoud Area'. (Source: Harmandayan Diran. B.H. brief city profile. Aout 2009.)

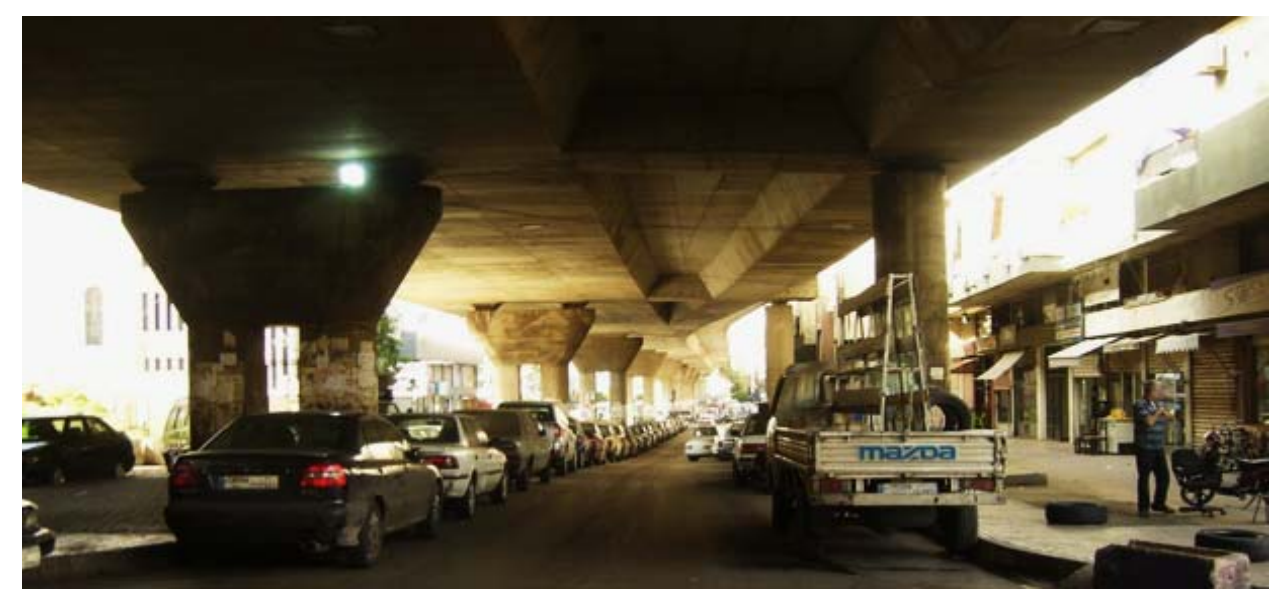

Figure 6: A Place under Yerevan Bridge. Most of sectors are built by single loaded columns. (Photo credit to Aram Papazian.) 
Iskandar Harb was the supervising engineer. The capacity comprises $2 \times 2$ lanes in two directions. The construction took eight years from 1997 to 2004 [8]. Cross sections, shown in Figs 7 and 8, represent distances between the bridge and the building that vary between $0.5 \mathrm{~m}$ to $2 \mathrm{~m}$. They show the T-Shape section that is based on mushroom columns.

\subsection{Disadvantages of 'Yerevan Bridge'}

The chosen example is located in an ever-changing urban environment. This structure does not only represent a source of noise, environmental and aesthetics pollution to its direct neighborhood. It is above all perceived as disconnecting the urban neighborhood relations. The bridge and its inhabitants seem as they are separated from the neighborhood with a feeling of repulsion. In this context, the Swiss architect Marc Mimram says:

\section{Infrastructure is an inevitable evil [9].}

The present form of the bridge has impoverished the adjacent spaces by blocking light and air and increasing pollutants, as shown in Fig. 9. It became a negative, undesired element for many residents.

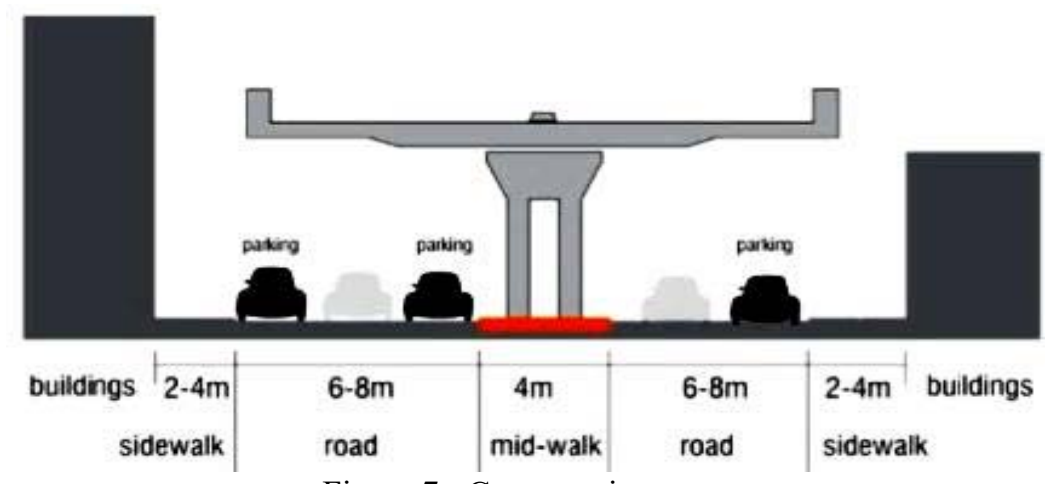

Figure 7: Cross section type.

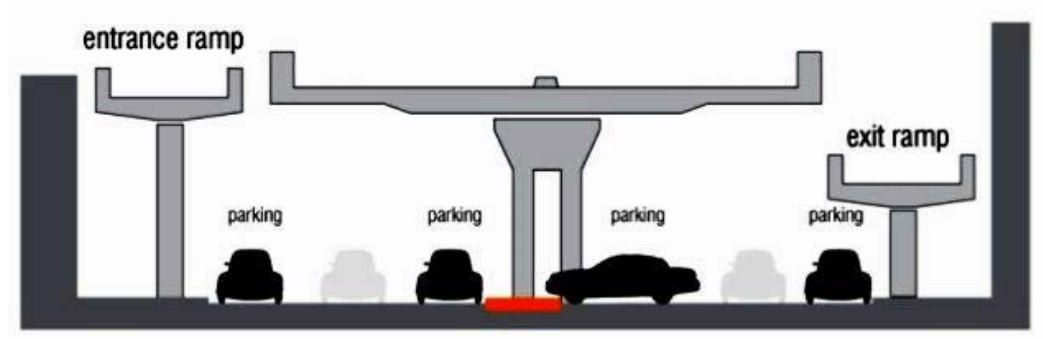

Figure 8: Cross section type at the level of ramps.
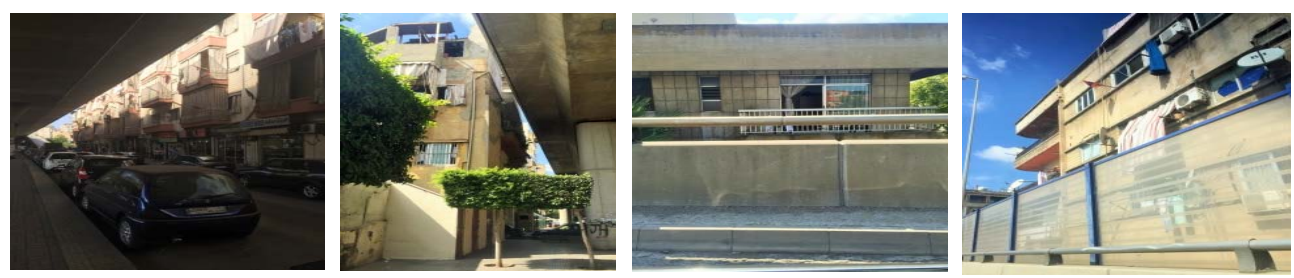

Figure 9: Shots for Yerevan Bridge adjacent to buildings distances between $0.5 \mathrm{~m}$ and $2 \mathrm{~m}$. 
Moreover, the Lebanese Law stipulates for security and environmental reasons; a minimal setback of 13 meters for buildings which are next to a highway. Nevertheless, such regulations become inapplicable in the event of highways built next to existing constructions.

\subsection{Face-to-face interviews}

The researcher undertook interviews, face to face, with a group of 50 people divided into four categories: residents between 35 and 45 years old living in the area adjacent to the bridge; shop merchants on both sides of the bridge; pedestrians using the passage under the bridge; and a group of experts in urban planning and architecture, as well as the resident architect of the municipality of Bourj Hammoud [10]. These interviews aimed to source opinions of different categories of people in order to determine the most critical problems regarding the places under Yerevan Bridge and trying to deduct effective solutions that can be applied in the future plan.

\subsubsection{Perspectives of the first three categories}

During interviews with residents, shop merchants, and pedestrians, the following questions were asked:

- How does Yerevan Bridge affect you as one of the residents of Bourj Hammoud Area or one of the merchants in this region?

- What are the negative and positive aspects which affected the area of Bourj Hammoud after establishing Yerevan Bridge?

- Do you use the public space under the bridge and in which manner?

A sample of the answers was said by the resident Ms. Mary, 40 years old:

"Despite the fact that the bridges facilitate the access of my children to their schools and workplaces, lighting easily accesses my house given the fact that I live in the third floor. My family cannot sleep day or night due to the annoying noise of vehicles which cross the bridge."

\subsubsection{Perspective of a group of experts}

Interviews were made with experts of planners and architects asking them similar questions to know their perspectives on the problems of this bridge and their proposed solutions. On one hand, comments were said supporting the idea of merging green spaces within the area. Rather, this merge is difficult horizontally on streets; it should be fulfilled vertically on the buildings, structures, whereas residents of the area entitled to green spaces for gathering, in addition to its psychological and physiological effects on humans. On the other hand, in Bourj Hammoud Municipality, a resident architect commented:

"Yerevan Bridge is considered newly established, namely in 2004, and two ramps were established, allowing access to the heart of Bourj Hammoud, but unfortunately buildings which are on both sides do not meet at all the environmental standards stipulated by the Lebanese laws".

\section{FINDINGS}

After procedures of the field methodology, the paper analyzes the findings. As a result, nearby dwellers are considered the most negatively affected category from establishing Yerevan Bridge, depending on their proximity to the bridge. Those who live below the 
bridge level suffer from lack of light and ventilation, while those residing in buildings higher than the bridge top level suffer from day lighting issue; as well as a ir and noise pollution resulting from vehicular movement. The charts, Figs 10 and 11, represent the percentage of the mentioned categories that are affected negatively because of the bridge.

From the charts, it can be found that the most category got affected negatively was the residents who were $70 \%$ of the sample. Out of the collected answers $70 \%$ show that traders and commercial establishments of the area under the bridge are the most benefitting party from the neglected zones under the bridge, where they have adapted the public space for commercial use, as shown in sketches of Fig. 12. On the other hand, residents complain that the same areas become unsafe and are a hub for illegal activity.

In Bourj Hammoud, there is mainly one public space, which is a city center garden square, shown in Fig. 13. Like in other parts of Beirut, streets become important public spaces that embody people's need. Streets are characterized by traffic, chaos, and ongoing interaction.

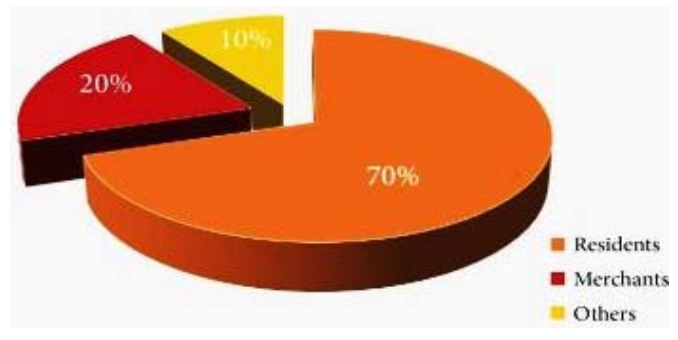

Figure 10: Negative effects on community.

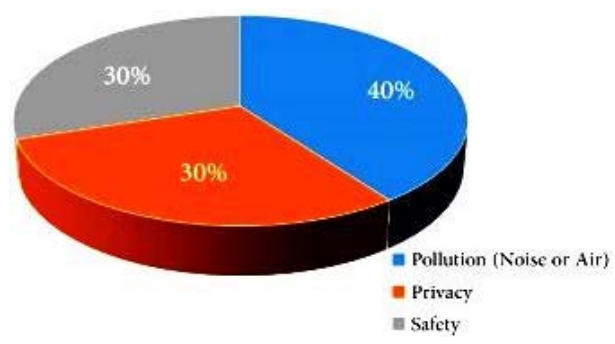

Figure 11: The affected users by the bridge.

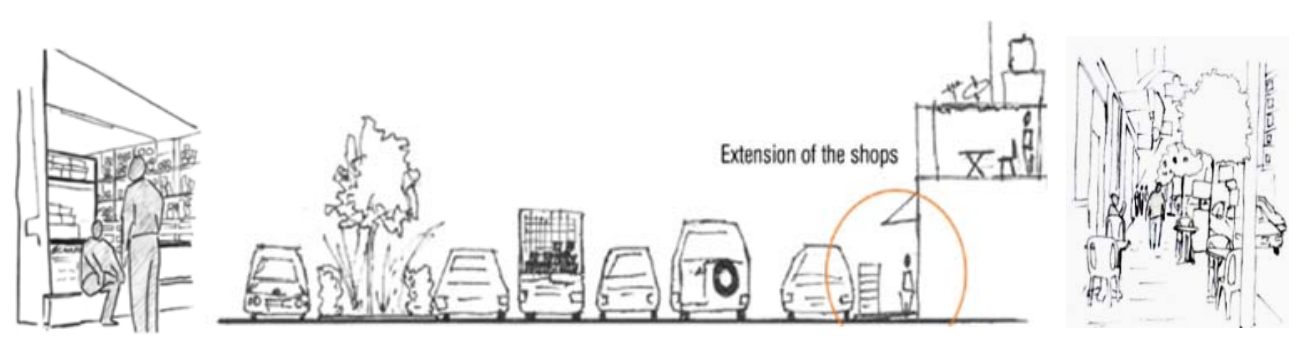

Figure 12: Merchants use the places under Yerevan Bridge as an extension of shops. (Source: Sketches drawn by Reem Saouma, 2008.) 

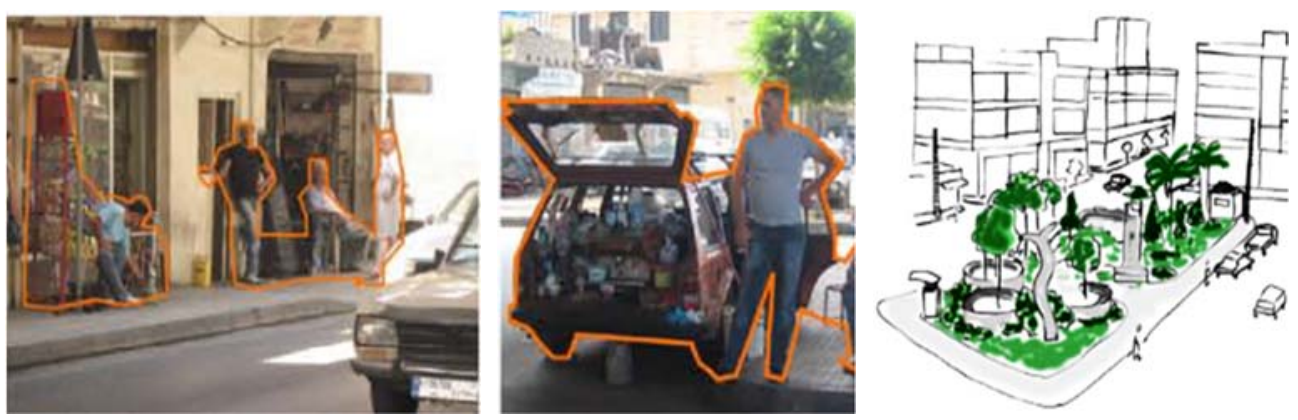

Figure 13: (a) On the left; Street characteristics; (b) On the right: A sketch for the city square, the only public space.
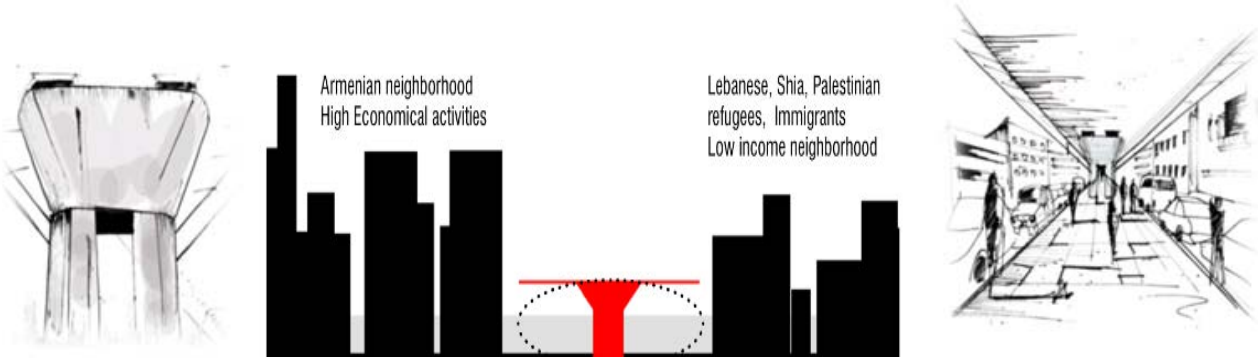

Figure 14: Yerevan bridge is a dominant structure with the urban fabric and cutting through the high dense between two different neighborhoods.

\section{DISCUSSION}

Based on the preceedings, Yerevan Bridge is an architectural element, ensuring the prompt access between the two districts of Achrafieh and Dekwaneh, and is considered a dominant structure within the urban fabric, as shown in Fig. 14, but it causes discontinuity in the local community and cuts the square, the only available public space of Bourj Hammoud Area. Planners and architects can change disadvantages of Yerevan Bridge into a positive potential through turning it into an inhabited bridge project. The present study proposes incorporating a new superstructure to the existing structure, in other words to transform 'Yerevan Bridge' into an inhabited bridge. This can be happened by formulating a new relationship between 'infrastructure' and 'superstructure'.

Based on the analysis of the findings, the paper produces certain solutions that can be followed to improve the present condition of Yerevan Bridge as follows:

- An urban solution: adding green areas and landscape elements can refresh the urban environment of the bridge.

- An urban solution: re-organizing places under the bridge by creating a sustainable promenade with various activities; commercial, entertainment, and cultural which may reduce pollution and erase beacons of dangers. 
- An architectural solution: a lower level bridge can be constructed under the existed bridge. This suspended structure can be a track for bicycles, a friendly passage for pedestrians with florist shops.

- An architectural solution: a screen of wooden Mashrabya/Arabesque can be installed on floors' elevations facing the bridge. This screen can give privacy to these floors' residents. To reduce noise of the passing vehicles, windows can be re-executed with triple glazed layers.

- An economic solution: some places under the bridge can be functioned as parking lots with limited fees. Trades of non-polluted goods can replace the heavy ones; such as, luxurious products, textile, or toys.

- A social solution: gathering areas can be designed under the bridge as spots of social activities for residents, children, and even merchants. A visionary solution of building light flying wooden bridges over the existed structure can connect between roofs of the residences which generate social interaction among residents.

These mentioned solutions can be a base of an intervention strategy, shown in Fig. 15, turning Yerevan Bridge into an inhabited bridge, reinventing the old idea of the inhabited bridges, but in simple urban and architectural solutions.

\section{CONCLUSION}

Finally, the paper ends up with a group of conclusions as follows:

a) Planners and architects should give the existed bridges more concern by adding new functions, rather than structural and transporting. These functions could be economic, social, environmental, or even residential.

b) Engineers and architects who work in the municipalities should deal with the neglected places under bridges seriously as dangerous spots with lack of light and air, reemploying them as amusement venues with landscape elements.

c) The idea of inhabited bridges can improve the informal/marginalized zones.

d) Merging infrastructure with the superstructure of an inhabited bridge requires a full comprehending of project's requirements such as; roads, capacity of vehicles, flow of pedestrians, dimensions, light directions, sustainable features that can be added to give lively actions to users and residents.

e) Transporting one from a point to a point requires a bridge; while changing a bridge to a potential vivid inhabited bridge requires an 'outside of the box' decision given by politicians and decision makers.

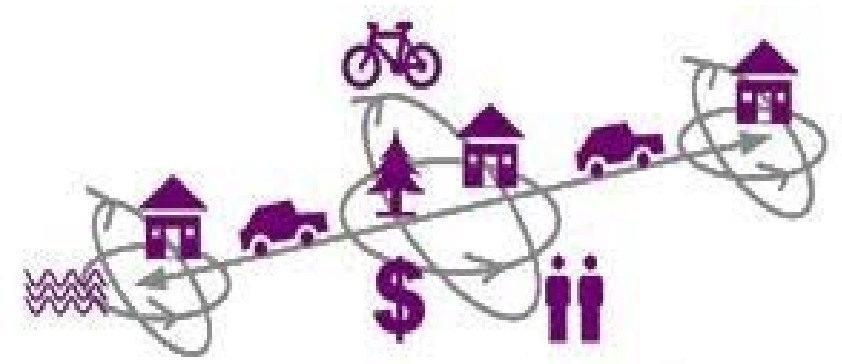

Figure 15: Elements of an intervention strategy can change Yerevan Bridge to be inhabited one. 


\section{REFERENCES}

[1] Procter, P., Cambridge International Dictionary of English. Cambridge University Press: London, England, 1995, Online. http://dictionary.cambridge. org/dictionary/english/bridge.

[2] Dethier, J., Inhabited Bridge. A speech in Conférence de Jean Dethier à l'Ecole d'Architecture Paris-Villette, 2013.

[3] Royal Academy of Arts (Great Britain), Living Bridges: the inhabited bridge, past, present and future, Prestel Press: Munich, Germany, p. 26, 1997.

[4] Paolini, C., Ponte Vecchio: Di pietra e di calcina (Quaderni), Edizioni Polistampa Press: Florence, Italy, p. 14, 2012. (In Italian)

[5] Dethier, J., Inhabited Bridge, Rassegna Serious, Birkhauser Verlag: Zurich, Switzerland, p. 43, 1995.

[6] Saouma, R., Landscape Architecture \& Planning, MSc. Thesis, Wageningen University: Netherlands, p. 30, 2008.

[7] Papazian, A., Bourj Hammoud, Online. http://storybuilder.jumpstart.ge/en/bourjhammoud. Accessed on: 28 Dec. 2016

[8] Harmandayan, D., Bourj Hammoud brief city profile, municipality of Bourj Hammoud, 2009.

[9] Jodidio, P., Marc Mimram: Architecture \& Structure, Prestel Press: New York, USA, p. 114, 2016.

[10] Face-to-face interview with sample of inhabitants of Bourj Hammoud. 